\title{
Post-Marketing Surveillance of Levofloxacin $0.5 \%$ Ophthalmic Solution for External Ocular Infections
}

\author{
Yoshiko Kanda, ${ }_{1}^{1}$ Tomoko Kayama, ${ }^{1}$ Shinji Okamoto, ${ }_{1}^{1}$ Masako Hashimoto, ${ }^{1}$ Chiemi Ishida ${ }^{2}$ \\ Tomoko Yanai, ${ }^{2}$ Mitsuru Fukumoto ${ }^{2}$ and Eiichi Kunihiro ${ }^{1}$ \\ 1 Post-Marketing Surveillance Group, Santen Pharmaceutical Co., Ltd., Osaka, Japan \\ 2 Drug Safety Information Group, Santen Pharmaceutical Co., Ltd., Osaka, Japan
}

\begin{abstract}
Background: Levofloxacin 0.5\% ophthalmic solution is an antibacterial formulation, which was approved and marketed for the treatment of ocular infections in Japan in 2000.

Objective: This study was designed to investigate the safety and efficacy of levofloxacin $0.5 \%$ ophthalmic solution in patients who received treatment for external ocular bacterial infections in regular clinical practice.

Methods: Patients were recruited from more than 800 medical facilities in Japan, in accordance with Japanese Ministry of Health, Labour and Welfare ordinance guidelines. They were followed during three distinct time periods: April 2000 to December 2001, January 2002 to June 2003, and July 2003 to December 2004.

Results: Information from 6760 patients receiving levofloxacin for the treatment of a variety of ocular infections was collected. Levofloxacin was well tolerated: adverse drug reactions (ADRs) were reported in 42 of 6686 patients $(0.63 \%)$, with no serious ADRs reported. The most commonly reported ADRs were ocular disorders such as blepharitis, eye irritation, and punctate keratitis. The incidence of ADRs did not differ significantly with age, but it was significantly higher in females $(0.82 \%)$ than in males $(0.36 \% ; \mathrm{p}=0.028)$. A clinical response was observed in $95.5 \%$ of patients receiving levofloxacin, with no difference in response between the three time periods. The rate of response to levofloxacin by bacterial disease ranged from $97.4 \%$ in keratitis to $88.3 \%$ in dacryocystitis. The rate was lower in patients with dacryocystitis, elderly patients, patients with a long duration of illness, and relapsing cases (all $\mathrm{p}<0.001$ ).

Conclusion: This post-marketing surveillance of levofloxacin, conducted over 4 years, confirms the safety and efficacy of levofloxacin in regular clinical use and highlights that levofloxacin is a promising treatment for a variety of external ocular bacterial infections.
\end{abstract}




\section{Introduction}

Levofloxacin $0.5 \%$ ophthalmic solution $\left(\mathrm{Cravit}^{\circledR}\right.$ ophthalmic solution $0.5 \%$; Santen Pharmaceutical Co., Ltd., Osaka, Japan) is an antibacterial eye drop formulation, which contains the active ingredient levofloxacin, a synthetic antimicrobial agent of the fluoroquinolone family. ${ }^{[1]}$ Fluoroquinolones are known to exert antimicrobial activity through inhibition of DNA gyrase, an enzyme involved in bacterial DNA synthesis. They have been used extensively for the treatment of bacterial infections in clinical practice because of their potent activity against a wide range of Gram-positive and Gram-negative microbes. Furthermore, topical fluoroquinolones, such as ophthalmic solutions containing norfloxacin or ofloxacin, have been widely prescribed for the treatment of external ocular bacterial infections. ${ }^{[2]}$

Levofloxacin, an L-isomer of ofloxacin, has two times greater antimicrobial activity than ofloxacin $^{[3]}$ and has high water solubility at a neutral $\mathrm{pH}$, allowing for the preparation of highconcentration formulations. Clinical trials of levofloxacin $0.5 \%$ ophthalmic solution revealed that levofloxacin ophthalmic solution was superior to ofloxacin ophthalmic solution. ${ }^{[4-7]}$ As a result, levofloxacin $0.5 \%$ ophthalmic solution was approved and marketed in Japan in 2000 for the treatment of bacterial conjunctivitis or other external ocular infections and for perioperative use during ocular surgery. ${ }^{[1]}$ It is approved for the treatment of bacterial conjunctivitis in the US (Quixin $\left.{ }^{\circledR}\right)^{[8]}$ and is also approved in several European countries for the treatment of ocular infections (Oftaquix ${ }^{\circledR}$ ). ${ }^{[9]}$

Japanese regulatory authority policy required monitoring of the safety and efficacy of levofloxacin $0.5 \%$ ophthalmic solution for the treatment of ocular bacterial infections for up to 6 years after its approval. In accordance with this, surveillance was conducted on the use of levofloxacin $0.5 \%$ ophthalmic solution, initiated immediately after levofloxacin was launched on the market. In this article, we present the results of this post-marketing surveillance of levofloxacin $0.5 \%$ ophthalmic solution used in everyday clinical practice in a large patient population.

\section{Methods}

\section{Patients}

This survey was designed to investigate the safety and efficacy of levofloxacin $0.5 \%$ ophthalmic solution in patients who received treatment for external ocular bacterial infections in regular clinical practice. Patients who had previously received levofloxacin $0.5 \%$ ophthalmic solution were excluded. Patients were recruited from more than 800 medical facilities in Japan, and treatment was based on the decision of the physician. The study protocol was set up in accordance with Ministry of Health, Labour and Welfare ordinance guidelines, ${ }^{[10,11]}$ and a contract with all medical facilities participating in this study was constructed. Written informed consent was not obtained, as Japanese law does not require informed consent for this type of noninterventional observational study.

\section{Study Design}

To eliminate bias in case extraction, a continuous investigation method was adopted, where patients were registered in chronological order depending on the time when treatment was initiated. Of these patients, those re-visiting the same medical facility were formally enrolled in the survey in chronological order (depending on the date of the first treatment with levofloxacin $0.5 \%$ ophthalmic solution) and entered into the case report form (CRF). The end of enrollment at each medical facility occurred at the time when the number of patients reached the number specified in that facility's contract.

The influence of the development of drugresistant bacterial strains on the efficacy of levofloxacin over time was also investigated, by conducting the survey in three distinct time periods: from April 2000 through to December 2001 (the first period), from January 2002 through to June 2003 (the second period), and from July 2003 through to December 2004 (the third period). The targeted number of patients was 2000 for each time period. 


\section{Survey Design and Analysis}

\section{Survey ltems}

The survey collected data pertaining to the background characteristics and demographics of each patient, the dosage and treatment duration of levofloxacin $0.5 \%$ ophthalmic solution, concomitant drugs and therapies, clinical symptoms of infection, adverse events associated with treatment, overall improvement, and bacteriological test data (if assessed).

\section{Safety}

Adverse events were defined as any medically unfavorable event taking place during or after treatment with levofloxacin $0.5 \%$ ophthalmic solution. Adverse drug reactions (ADRs) were considered treatment related if a causal relationship with levofloxacin $0.5 \%$ ophthalmic solution could not be ruled out.

\section{Efficacy}

The efficacy of levofloxacin $0.5 \%$ ophthalmic solution was assessed by the physicians in charge of each medical center, using a three-category scale. The overall change was rated as 'improved', 'unchanged', or 'worsened'. Clinical response rates were assessed, using the following calculation:

$$
\text { Response rate }(\%)=\frac{\text { No. of improved patients }}{\begin{array}{c}
\text { Total no. of patients included } \\
\text { in efficacy evaluation }
\end{array}} \times 100
$$

\section{Study Populations and Statistical Analysis}

The safety analysis population included all patients who completed a CRF, excluding cases that violated the study protocol (including violation of the continuous investigation method, redundantly enrolled patients, etc.). The efficacy analysis population included all CRFs that were included in the safety population, excluding cases that received levofloxacin $0.5 \%$ ophthalmic solution for diseases other than external ocular bacterial infections and cases where the physician was unable to judge the overall improvement of the disease to treatment. The Pearson's $\chi^{2}$ test and the Cochran-Armitage test were used for analysis of safety and efficacy data. A p-value of $<0.05$ (two-tailed) was regarded as statistically significant. The Medical Dictionary for Regulatory Activities/Japanese Edition (MedDRA/J) version 8.1 was employed for classifying ADRs.

\section{Results}

\section{Patient Recruitment and Populations}

During the three periods of surveillance, CRFs for 6760 patients were collected from 808 medical centers, including ophthalmology departments at 14 university hospitals, 22 national/public hospitals, 20 quasi-public hospitals, and 62 other hospitals, as well as 690 ophthalmic general practitioners. CRFs were completed for 2399 patients during the first time period (from 314 medical centers), 2133 patients during the second period (293 medical centers), and 2228 patients during the third period (290 medical centers). Of these 6760 cases, 74 cases were excluded from the safety evaluation, with the remaining 6686 cases being included in the safety analysis. Of these, 757 cases were excluded from the efficacy evaluation, with the remaining 5929 cases being included in the efficacy analysis (figure 1).

\section{Treatment Duration}

The median dosing period, which was assumed to be the duration of treatment required to cure the disease, was 8 days for hordeolum, keratitis, and corneal ulcers; 9 days for conjunctivitis; and 10 days for blepharitis and tarsadenitis. In comparison, it was 29 days for dacryocystitis (figure 2). Levofloxacin $0.5 \%$ ophthalmic solution was administered 3-4 times daily in patients with blepharitis, dacryocystitis, hordeolum, conjunctivitis, and tarsadenitis; 4 times daily in patients with keratitis; and 4-6 times daily in patients with corneal ulcers (table I).

\section{Safety}

\section{Adverse Drug Reactions}

Of the 6686 patients included in the safety evaluation, 46 ADRs were reported in 42 patients. The overall incidence of ADRs was $0.63 \%$. The most commonly reported ADRs were ocular disorders such as blepharitis (7 cases, $0.10 \%$ ), eye irritation (6 cases, $0.09 \%$ ) and punctate keratitis 


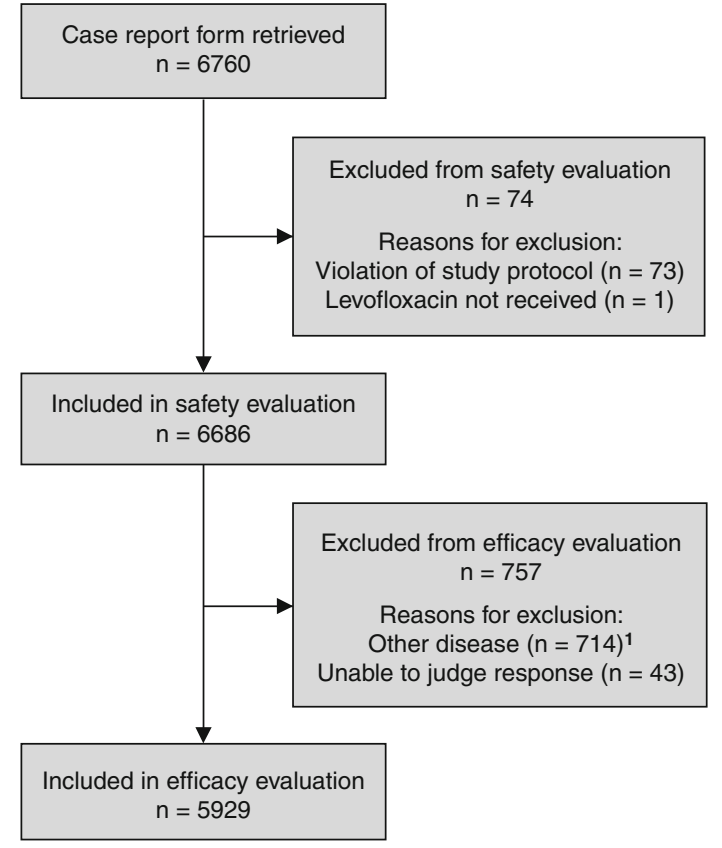

1 These patients received levofloxacin $0.5 \%$ ophthalmic solution for a disease other than external ocular bacterial infection.

Fig. 1. Patient populations included in the safety and efficacy analyses of levofloxacin $0.5 \%$ ophthalmic solution.

(5 cases, 0.07\%). None of the 46 ADRs reported were considered serious (table II).

\section{Adverse Drug Reactions According to Patient Demographics and Dosing Frequency of Levofloxacin}

Table III lists the ADRs reported during the post-marketing surveillance of levofloxacin $0.5 \%$ ophthalmic solution, according to patient demographics and the dosing frequency of levofloxacin. Of interest, the incidence of ADRs was significantly higher in females $(0.82 \%)$ than in males $(0.36 \% ; p=0.028)$, and eye irritation and eye pruritus were reported only in females. Of the 3904 women surveyed, seven were pregnant; none reported any adverse events with administration of levofloxacin $0.5 \%$ ophthalmic solution. However, no information pertaining to the effects of levofloxacin $0.5 \%$ ophthalmic solution on labor or on the health of the newborn was collected.
There was no correlation between the age of the patient and the incidence of ADRs (table III). In patients aged $<15$ years, the incidence of ADRs was $0.32 \%$, which was no higher than those reported in patients aged $\geq 15$ and $<65$ years or in patients aged $\geq 65$ years $(0.62 \%$ and $0.81 \%$, respectively). ADRs were found in four children: punctate keratitis (1 case), eye pruritus (1 case), dermatitis contact (1 case), and urticaria (1 case). No ADRs were reported in patients younger than 1 year old.

As for the dosing frequency of levofloxacin, the incidence of ADRs did not differ significantly depending on the mean daily frequency of treatment with levofloxacin $0.5 \%$ ophthalmic solution.

\section{Efficacy}

\section{Clinical Response}

A clinical response was observed in $95.5 \%$ of the 5929 patients included in the efficacy population. Response rates did not differ significantly between the three time periods of the survey $\left(\mathrm{p}=0.099, \chi^{2}\right.$ test). Clinical response was observed in $94.7 \%$ of patients in the first time period, $95.9 \%$ of patients in the second time period, and $95.9 \%$ of patients in the third time period.

\section{Response Rates According to Disease Diagnosis}

The rates of clinical response to treatment with levofloxacin $0.5 \%$ ophthalmic solution are summarized in table IV, according to the type of external ocular bacterial infection that was reported. Cases where patients were diagnosed with two or more diseases were counted in each disease group. Response rates were similar for most types of external ocular infection; however, the response rate was $88.3 \%$ in patients who were diagnosed with dacryocystitis, which was significantly lower than the response rate observed in patients who were diagnosed with any other type of ocular infection $(95.8 \%$; $p<0.001)$.

The clinical response rates in patients with hordeolum and conjunctivitis differed significantly between the three investigational time periods $(\mathrm{p}=0.027$ and $\mathrm{p}=0.019$, respectively). However, these response rates did not decrease over time. 


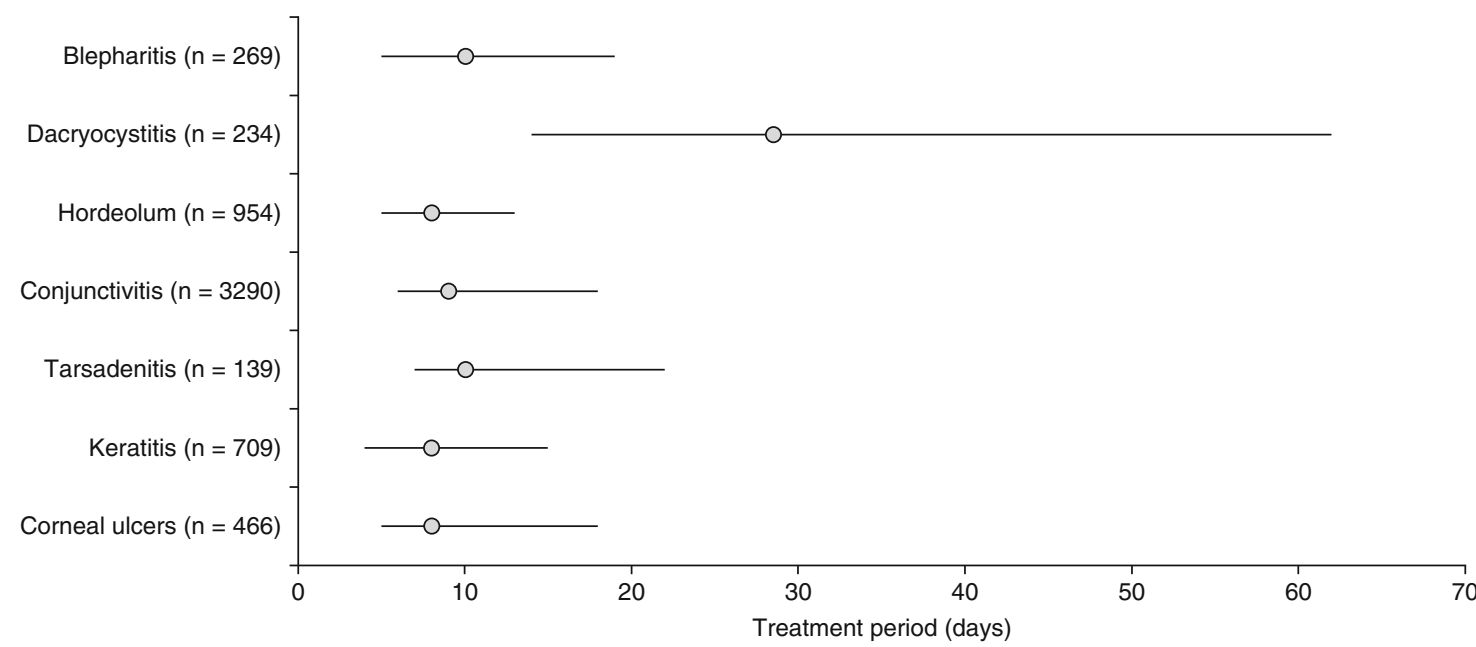

Fig. 2. Median duration of treatment with levofloxacin $0.5 \%$ ophthalmic solution in responders, according to ocular disease type. The gray data-point markers indicate median values, and the horizontal data lines indicate 25 th-75th percentile ranges.

\section{Response Rates According to Type of Bacteric} Isolated

Of the 5929 patients included in the efficacy evaluation, 1814 patients underwent a bacteriological test at the start of treatment with levofloxacin $0.5 \%$ ophthalmic solution. Bacteria were isolated from 1152 patients, and the response rate of these patients was analyzed according to the type of bacteria that was isolated (table V). Cases where two or more strains of bacteria were isolated were counted in each bacterial group. The response rates were around $90 \%$ for major bacterial strains of external ocular infections, such as Staphylococcus spp., Streptococcus spp., Streptococcus pneumoniae, Corynebacterium spp., and Haemophilus influenzae. When the response rates for each bacterial strain were compared between the three time periods, there was no strain whose response rate differed significantly between the time periods.

\section{Response Rates According to Background} Demographics and Characteristics

Table VI shows the efficacy of levofloxacin $0.5 \%$ ophthalmic solution, according to background demographics and characteristics. Age, duration of illness, and disease history all significantly affected the response to treatment (all $p<0.001)$. As age advanced, response rates were lower. Furthermore, lower clinical response rates were reported in patients who had a longer duration of ocular disease or who had relapsed.

\section{Discussion}

Clinical trials for new-drug applications are generally carried out in controlled environments with limitations set on various factors, including the number of enrolled patients, the age of the patients, the presence of disease complications, and the use of concomitant drugs. For this reason, the information provided by clinical trials

Table I. Median daily dosing frequency of levofloxacin $0.5 \%$ ophthalmic solution, according to disease

\begin{tabular}{lrl}
\hline Disease & $\mathrm{N}$ & $\begin{array}{l}\text { Median daily dosing frequency } \\
\text { [25th-75th percentile] }\end{array}$ \\
\hline Blepharitis & 269 & $4.00[3.00-4.00]$ \\
Dacryocystitis & 230 & $4.00[3.00-4.00]$ \\
Hordeolum & 954 & $4.00[3.00-4.00]$ \\
Conjunctivitis & 3289 & $4.00[3.00-4.00]$ \\
Tarsadenitis & 139 & $4.00[3.00-4.00]$ \\
Keratitis & 708 & $4.00[4.00-4.00]$ \\
Corneal ulcers & 466 & $4.64[4.00-6.00]$ \\
\hline
\end{tabular}


Table II. Adverse drug reactions associated with levofloxacin $0.5 \%$ ophthalmic solution reported in the 804 facilities surveyed (safety population: $\mathrm{N}=6686$ )

\begin{tabular}{ll}
\hline ADR & $\mathrm{n}[\%]$ \\
\hline No. of patients reporting any ADR & $42[0.63]$ \\
No. of ADRs reported & 46 \\
Nervous system disorders & $1[0.01]$ \\
Numbness of fingers & $1[0.01]$ \\
Eye disorders & $39[0.58]$ \\
Corneal erosion & $2[0.03]$ \\
Keratitis & $4[0.06]$ \\
Corneal epithelium disorder & $1[0.01]$ \\
Punctate keratitis & $5[0.07]$ \\
Eye pruritus & $3[0.04]$ \\
Eyelids pruritus & $1[0.01]$ \\
Foreign body sensation in eyes & $1[0.01]$ \\
Eye irritation & $6[0.09]$ \\
Eye pain & $2[0.03]$ \\
Ocular discomfort & $1[0.01]$ \\
Blepharitis & $7[0.10]$ \\
Eyelid edema & $2[0.03]$ \\
Conjunctivitis & $2[0.03]$ \\
Conjunctival hyperemia & $2[0.03]$ \\
Episcleritis & $1[0.01]$ \\
Lacrimation increased & $2[0.03]$ \\
Gastrointestinal disorders & $1[0.01]$ \\
Oral numbness & $1[0.01]$ \\
Skin and subcutaneous tissue disorders & $2[0.03]$ \\
Dermatitis contact & $1[0.01]$ \\
Urticaria & $1[0.01]$ \\
\hline ADR =adverse drug reaction. & \\
\hline & \\
\hline
\end{tabular}

cannot always predict the efficacy and safety of a drug in the real-world setting, and it is important to collect and evaluate further data on safety and efficacy in the post-marketing setting. This study was undertaken to survey the post-marketing use, safety, and efficacy of levofloxacin $0.5 \%$ ophthalmic solution for the treatment of external ocular bacterial infections over three distinct time periods in Japan.

Our study suggested that levofloxacin $0.5 \%$ ophthalmic solution is well tolerated in a large patient population. The proportion of patients with ADRs was less than $1 \%$. This is comparable to the reported incidence of ADRs associated with other fluoroquinolone ophthalmic solutions (ofloxacin, lomefloxacin, and norfloxacin) in post-marketing surveillance studies in Japan. ${ }^{[12-14]}$ Furthermore, in our study, no serious ADRs were reported. ADRs were reported more frequently in females than in males. However, this finding does not seem to be specific to levofloxacin $0.5 \%$ ophthalmic solution. A post-marketing surveillance report of another ophthalmic solution used for the treatment of allergic conjunctivitis also demonstrated a higher incidence of ADRs, such as eye irritation, in females. ${ }^{[15]}$ In the pre-marketing clinical trials of levofloxacin $0.5 \%$ ophthalmic solution, there were insufficient data to determine the safety and efficacy of treatment in the pediatric setting, as only 16 children received levofloxacin ophthalmic solution (including ones who received the $0.3 \%$

Table III. Adverse drug reactions associated with levofloxacin $0.5 \%$ ophthalmic solution, according to patient demographics and frequency of levofloxacin dosing

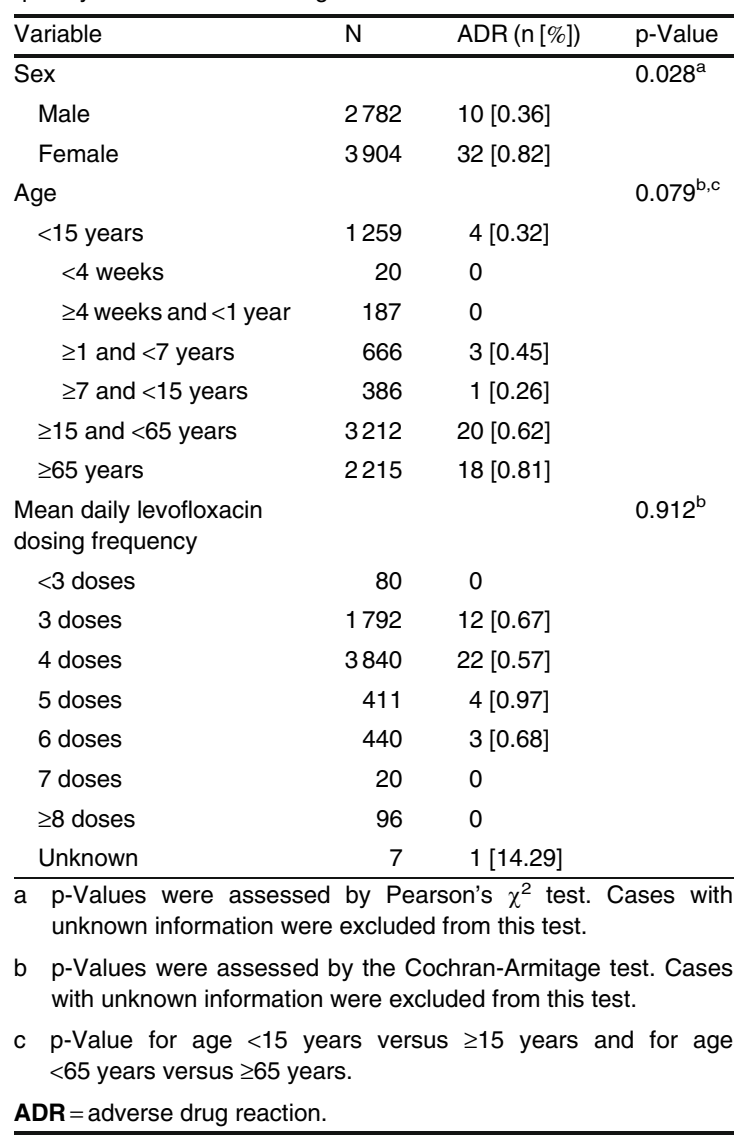


Table IV. Rates of response to levofloxacin $0.5 \%$ ophthalmic solution, according to disease

\begin{tabular}{|c|c|c|c|c|c|}
\hline Disease & $\begin{array}{l}\text { Total } \\
(\%[\mathrm{n} / \mathrm{N}])\end{array}$ & $\begin{array}{l}\text { First period } \\
(\%[\mathrm{n} / \mathrm{N}])\end{array}$ & $\begin{array}{l}\text { Second period } \\
(\%[n / N])\end{array}$ & $\begin{array}{l}\text { Third period } \\
(\%[\mathrm{n} / \mathrm{N}])\end{array}$ & $\mathrm{p}$-Value ${ }^{\mathrm{a}}$ \\
\hline Blepharitis & 96.4 [269/279] & 95.7 [89/93] & $95.3[81 / 85]$ & $98.0[99 / 101]$ & 0.548 \\
\hline Dacryocystitis & 88.3 [234/265] & $89.5[128 / 143]$ & $88.9[64 / 72]$ & $84.0[42 / 50]$ & 0.570 \\
\hline Hordeolum & $94.2[954 / 1013]$ & $93.4[309 / 331]$ & $92.2[309 / 335]$ & 96.8 [336/347] & 0.027 \\
\hline Conjunctivitis & $95.5[3292 / 3446]$ & $94.4[1208 / 1279]$ & $96.9[1017 / 1050]$ & $95.5[1067 / 1117]$ & 0.019 \\
\hline Tarsadenitis & $95.2[139 / 146]$ & $93.8[60 / 64]$ & $97.8[45 / 46]$ & $94.4[34 / 36]$ & 0.596 \\
\hline Keratitis $^{b}$ & $97.4[1159 / 1190]$ & $97.2[346 / 356]$ & $97.5[396 / 406]$ & $97.4[417 / 428]$ & 0.954 \\
\hline
\end{tabular}

a $p$-Values were assessed by Pearson's $\chi^{2}$ test and are for the first period versus the second period versus the third period.

b Including corneal ulcers.

preparation). This study collected data on the use of levofloxacin in 1259 children and showed that levofloxacin $0.5 \%$ ophthalmic solution can be used safely in children. ADRs were reported in only $0.32 \%$ of the children, which was not higher than the rates reported in patients in the other age groups.

This study also suggested that levofloxacin $0.5 \%$ ophthalmic solution is effective in everyday clinical practice. The clinical response rate of ex- ternal ocular bacterial infections was high, with $95.5 \%$ of all patients included in the efficacy analysis reporting a clinical response. In the subgroup analysis, the rate was lower in patients with dacryocystitis, elderly patients, patients with a long duration of illness, and relapsing cases. Dacryocystitis is typically a difficult disease to treat, and it appears that a longer duration of illness or a relapse of illness is also associated with

Table V. Rates of response to levofloxacin $0.5 \%$ ophthalmic solution, according to bacteria isolated ${ }^{\mathrm{a}}$

\begin{tabular}{|c|c|c|c|c|c|}
\hline Bacteria & $\begin{array}{l}\text { Total } \\
(\%[\mathrm{n} / \mathrm{N}])\end{array}$ & $\begin{array}{l}\text { First period } \\
(\%[\mathrm{n} / \mathrm{N}])\end{array}$ & $\begin{array}{l}\text { Second period } \\
(\%[\mathrm{n} / \mathrm{N}])\end{array}$ & $\begin{array}{l}\text { Third period } \\
(\%[\mathrm{n} / \mathrm{N}])\end{array}$ & $\overline{p-V_{a l u e}}$ \\
\hline Staphylococcus spp. & $93.5[561 / 600]$ & $92.7[316 / 341]$ & $96.5[137 / 142]$ & $92.3[108 / 117]$ & 0.254 \\
\hline Streptococcus spp. & $88.5[77 / 87]$ & $84.9[45 / 53]$ & $95.2[20 / 21]$ & $92.3[12 / 13]$ & 0.407 \\
\hline Streptococcus pneumoniae & $95.9[93 / 97]$ & $98.3[58 / 59]$ & $89.5[17 / 19]$ & $94.7[18 / 19]$ & 0.233 \\
\hline Enterococcus spp. & 100 [22/22] & $100[13 / 13]$ & $100[3 / 3]$ & $100[6 / 6]$ & NA \\
\hline Micrococcus spp. & $100[2 / 2]$ & $100[1 / 1]$ & ND & $100[1 / 1]$ & NA \\
\hline Moraxella spp. & $96.7[29 / 30]$ & $100[11 / 11]$ & $100[11 / 11]$ & $87.5[7 / 8]$ & 0.241 \\
\hline Corynebacterium spp. & $93.5[186 / 199]$ & $93.9[124 / 132]$ & $93.8[30 / 32]$ & $91.4[32 / 35]$ & 0.864 \\
\hline Klebsiella spp. & $100[7 / 7]$ & $100[3 / 3]$ & $100[3 / 3]$ & $100[1 / 1]$ & NA \\
\hline Enterobacter spp. & $100[10 / 10]$ & $100[6 / 6]$ & ND & $100[4 / 4]$ & NA \\
\hline Serratia spp. & $100[30 / 30]$ & $100[18 / 18]$ & $100[5 / 5]$ & $100[7 / 7]$ & NA \\
\hline Proteus spp. & $100[4 / 4]$ & $100[1 / 1]$ & $100[2 / 2]$ & $100[1 / 1]$ & NA \\
\hline Morganella morganii & $85.7[6 / 7]$ & $100[3 / 3]$ & $50.0[1 / 2]$ & $100[2 / 2]$ & 0.232 \\
\hline Haemophilus influenzae & $98.9[181 / 183]$ & $98.8[81 / 82]$ & $97.8[45 / 46]$ & $100[55 / 55]$ & 0.572 \\
\hline $\begin{array}{l}\text { Haemophilus aegyptius } \\
\text { (Koch-Weeks bacillus) }\end{array}$ & $100[1 / 1]$ & $100[1 / 1]$ & ND & ND & NA \\
\hline Pseudomonas spp. & $100[20 / 20]$ & $100[12 / 12]$ & $100[4 / 4]$ & $100[4 / 4]$ & NA \\
\hline Pseudomonas aeruginosa & $80.8[21 / 26]$ & $83.3[15 / 18]$ & $80.0[4 / 5]$ & $66.7[2 / 3]$ & 0.793 \\
\hline $\begin{array}{l}\text { Stenotrophomonas } \\
\text { (Xanthomonas) maltophilia }\end{array}$ & $71.4[5 / 7]$ & $66.7[4 / 6]$ & ND & $100[1 / 1]$ & 1.000 \\
\hline Acinetobacter spp. & $82.8[24 / 29]$ & $83.3[15 / 18]$ & $80.0[4 / 5]$ & $83.3[5 / 6]$ & 0.984 \\
\hline Propionibacterium acnes & $85.7[6 / 7]$ & $83.3[5 / 6]$ & ND & $100[1 / 1]$ & 1.000 \\
\hline
\end{tabular}


Table VI. Rates of response to levofloxacin $0.5 \%$ ophthalmic solution, according to patient demographics and disease characteristics

\begin{tabular}{|c|c|c|c|}
\hline Variable & $\mathrm{N}$ & $\begin{array}{l}\text { Response } \\
\text { (n [\%]) }\end{array}$ & $p$-Value \\
\hline \multicolumn{3}{|l|}{$\overline{\text { Sex }}$} & $0.125^{a}$ \\
\hline Male & 2415 & 2318 [96.0] & \\
\hline Female & 3514 & $3342[95.1]$ & \\
\hline \multicolumn{3}{|l|}{ Age } & $<0.001^{\mathrm{b}, \mathrm{c}}$ \\
\hline$<15$ years & 1167 & $1142[97.9]$ & \\
\hline$<4$ weeks & 19 & $19[100]$ & \\
\hline$\geq 4$ weeks and $<1$ year & 178 & $173[97.2]$ & \\
\hline$\geq 1$ and $<7$ years & 622 & $612[98.0]$ & \\
\hline$\geq 7$ and $<15$ years & 348 & $338[97.1]$ & \\
\hline$\geq 15$ and $<65$ years & 2788 & $2670[95.8]$ & \\
\hline$\geq 65$ years & 1974 & $1848[93.6]$ & \\
\hline \multicolumn{3}{|l|}{ Duration of illness } & $<0.001^{\mathrm{b}}$ \\
\hline $1-2$ days & 2692 & $2603[96.7]$ & \\
\hline 3-4 days & 1213 & $1181[97.4]$ & \\
\hline 5-7 days & 393 & $376[95.7]$ & \\
\hline 8-29 days & 536 & $506[94.4]$ & \\
\hline$\geq 30$ days & 255 & $222[87.1]$ & \\
\hline Unknown & 840 & 772 [91.9] & \\
\hline \multicolumn{3}{|l|}{ First onset/relapse } & $<0.001^{\mathrm{a}}$ \\
\hline First onset & 5094 & $4917[96.5]$ & \\
\hline Relapse & 475 & $416[87.6]$ & \\
\hline Unknown & 360 & $327[90.8]$ & \\
\hline \multicolumn{4}{|c|}{$\begin{array}{l}\mathrm{p} \text {-Values were assessed by Pearson's } \chi^{2} \text { test. } \\
\text { unknown information were excluded from this test. }\end{array}$} \\
\hline \multicolumn{4}{|c|}{$\begin{array}{l}\text { b p-Values were assessed by the Cochran-Armitage test. Cases } \\
\text { with unknown information were excluded from this test. }\end{array}$} \\
\hline \multicolumn{4}{|c|}{$\begin{array}{l}\text { c } p \text {-Value for age }<15 \text { years versus } \geq 15 \text { years and for age } \\
<65 \text { years versus } \geq 65 \text { years. }\end{array}$} \\
\hline
\end{tabular}

lower efficacy. Furthermore, the low response rate observed in this study in elderly patients seems to be attributable to a high percentage of patients with dacryocystitis, cases with a long duration of illness, and relapsing cases.

The clinical response observed with levofloxacin $0.5 \%$ ophthalmic solution was not reduced over time or when analyzed according to the type of ocular disease or the type of bacterium involved. In parallel with this post-marketing surveillance, a drug sensitivity test was conducted to evaluate the susceptibility of fresh clinically isolated bacterial strains (derived from patients with ocular infection) to levofloxacin and other drugs. ${ }^{[16-18]}$ This test indicated that the bacterial strains associated with ocular infections did not tend to develop resistance to levofloxacin over time. However, it is important to monitor for the possible development of drug-resistant strains in the future, because bacterial strains with minimal inhibitory concentrations higher than $128 \mu \mathrm{g} / \mathrm{mL}$ were found among methicillin-resistant Staphylococcus aureus and Corynebacterium spp. soon after the marketing of levofloxacin $0.5 \%$ ophthalmic solution, and there was a report of cases developing infection with levofloxacin-resistant Corynebacterium spp. via the sutures. ${ }^{[19]}$

Treatment with levofloxacin $0.5 \%$ ophthalmic solution was completed within 10 days in $50 \%$ of the cases. This is ideal, because the disappearance of major symptoms within 2 weeks of treatment is one of the criteria used to determine a clinical response according to the Japanese criteria for evaluation of antimicrobial ophthalmic solutions. ${ }^{[20]}$ However, the treatment period was longer and the response rate was lower in patients with dacryocystitis than in patients with other infections. As discussed above, treatment of dacryocystitis with an ophthalmic solution alone seems to be insufficient. This is because the duration of dacryocystitis is often longer than those of other ocular infections; dacryocystitis is often relapsing in nature; and surgical treatments, such as dacryocystorhinostomy, are often necessary for the treatment of this disease, as it can obstruct the nasolacrimal duct. ${ }^{[21]}$ As for the dosing frequency of levofloxacin $0.5 \%$ ophthalmic solution, it was higher in patients with bacterial corneal ulcers than in patients with other ocular diseases. This is because if corneal ulcers are aggravated, visual disorders may occur. Because of this, the Japanese guidelines on management of infectious keratitis, which were made public in October 2007, recommend frequent application of antimicrobial ophthalmic solution in patients with severe infectious keratitis. ${ }^{[22]}$ This study also indicates that when treating bacterial corneal ulcers, treatment can be completed within 8 days in half of all cases if levofloxacin $0.5 \%$ ophthalmic solution is applied 4-6 times daily. Increasing the frequency of dosing of levofloxacin $0.5 \%$ ophthalmic solution did not elevate the incidence of ADRs. 


\section{Conclusion}

This post-marketing surveillance of levofloxacin $0.5 \%$ ophthalmic solution $\left(\mathrm{Cravit}^{\circledR}\right.$ ophthalmic solution), conducted over 4 years, confirms the safety and efficacy of levofloxacin $0.5 \%$ ophthalmic solution in regular clinical use and highlights that it is a promising treatment for a variety of external ocular bacterial infections.

\section{Acknowledgments}

This study was originally published in Japanese in Rinsho Ganka, the Japanese Journal of Clinical Ophthalmology. ${ }^{[23]}$ The study has been reproduced here in English with kind permission of the publisher of Rinsho Ganka, Igaku-Shoin Ltd. The authors would like to thank Simone Boniface of inScience Communications, Springer Healthcare, who provided medical writing assistance (funded by Santen Pharmaceutical Co., Ltd.); Akio Nomura of Santen Pharmaceutical Co., Ltd., for reviewing and editing the paper; and the healthcare professionals who participated in this study and gave their cooperation with the survey and supply of valuable data.

At the time when this research was conducted, all authors were employees of Santen Pharmaceutical Co., Ltd., which manufactures the product described in this research.

\section{References}

1. Cravit ${ }^{\circledR}$ ophthalmic solution: prescribing information. Osaka: Santen Pharmaceutical Co., Ltd., 2005 Oct

2. Rose P. Management strategies for acute infective conjunctivitis in primary care: a systematic review. Expert Opin Pharmacother 2007 Aug; 8 (12): 1903-21

3. Une T, Fujimoto T, Sato K, et al. In vitro activity of DR3355, an optically active ofloxacin. Antimicrob Agents Chemother 1988 Sep; 32 (9): 1336-40

4. Usui M. Clinical evaluation of levofloxacin ophthalmic solution: phase III open label trial [in Japanese]. Atarashii Ganka 1997; 14 (7): 1113-8

5. Usui M. Clinical evaluation of levofloxacin ophthalmic solution: a multicenter phase III double-masked clinical trial [in Japanese]. Atarashii Ganka 1997; 14 (4): 641-8

6. Usui M. Clinical evaluation of levofloxacin ophthalmic solution: a multicenter phase II double-masked clinical trial [in Japanese]. Atarashii Ganka 1997; 14: 299-307

7. Usui M. Effect of levofloxacin ophthalmic solution on preoperative sterilization [in Japanese]. Atarashii Ganka 1997; 14 (6): 953-6

8. Quixin ${ }^{\circledR}$ (levofloxacin ophthalmic solution) $0.5 \%$ : prescribing information [online]. Available from URL: http:// www.quixin.com/ [Accessed 2012 May 22]

9. Santen Pharmaceutical Co., Ltd. Products in Europe [online]. Available from URL: http://www.santen.eu/eu/ products/Pages/default.aspx [Accessed 2012 May 22]

10. Ministry of Health, Labour and Welfare. Ministerial ordinance on good post-marketing surveillance practice
(GPMSP) no. 10. Tokyo: Ministry of Health, Labour and Welfare, 1997 Mar 3

11. Pharmaceutical and Food Safety Bureau, Ministry of Health, Labour and Welfare. Guidelines on methods of clinical use result surveys on ethical drugs (notification no. 34). Tokyo: Ministry of Health, Labour and Welfare, 1997 Mar 27

12. Santen Pharmaceutical Co., Ltd. Tarivid ${ }^{\circledR}$ ophthalmic solution $0.3 \%$ (ofloxacin ophthalmic solution): interview form [online]. Available from URL: http://www.santen.co.jp medical/common/pdf/info_package/if/tarivid.pdf [Accessed 2012 May 22]

13. Senju Pharmaceutical Co., Ltd. Lomeflon ${ }^{\circledR}$ ophthalmic solution $0.3 \%$ (lomefloxacin ophthalmic solution): interview form [online]. Available from URL: http://www.senju.co. $\mathrm{jp} /$ medical/products/ icsFiles/afieldfile/2011/09/26/rm. pdf [Accessed 2012 May 22]

14. Nichi-Iko Pharmaceutical Co., Ltd. Noflo ${ }^{\circledR}$ ophthalmic solution $0.3 \%$ (norfloxacin ophthalmic solution $0.3 \%$ ): package insert [online]. Available from URL: http:// www.info.pmda.go.jp/go/pack/1319727Q1158_2_02/[Accessed 2012 May 22]

15. Oshima K, Kojima C, Sawada S, et al. Postmarketing survey of ibudilast $\left(\right.$ Eyevinal $^{\circledR}$ ) ophthalmic solution in allergic conjunctivitis: drug use results survey [in Japanese]. Atarashii Ganka 2004; 21: 1419-27

16. Matsuzaki K, Koyama H, Watanabe E, et al. Antimicrobial susceptibility surveillance of recent isolates from ophthalmological infections to levofloxacin and other antimicrobial drugs [in Japanese]. Antibiotics \& Chemotherapy 2003; 19: 431-40

17. Matsuzaki K, Watanabe E, Shikano M, et al. Susceptibility of ocular infection isolates to levofloxacin and other antimicrobial drugs [in Japanese]. Atarashii Ganka 2004; 21 (11): $1539-46$

18. Kobayashi I, Matsuzaki K, Shitou K, et al. Surveillance of ocular infection isolate susceptibility to levofloxacin and other antimicrobial drugs [in Japanese]. Atarashii Ganka 2006; 23 (2): 237-43

19. Kakimaru A, Kawaguchi A, Mihara E. Suture abscess of levofloxacin-resistant Corynebacterium spp. [in Japanese]. Atarashii Ganka 2004; 21: 801-4

20. Mitsui Y, Kitano S, Uchida Y, et al. Standardization of the evaluation of antimicrobial ophthalmic solutions and ointments, 1985 [in Japanese]. Nippon Ganka Gakkai Zasshi 1986; 90 (3): 511-5

21. Kameyama K. Dacryocystitis. In: Usui M, Ohashi Y, Tagawa Y, et al., editors. Ocular infections clinic [in Japanese]. Tokyo: Igaku-shoin Ltd., 2000: 138-9

22. Japanese Association for Ocular Infection. Guidelines for the clinical management of infectious keratitis [in Japanese]. Nippon Ganka Gakkai Zasshi 2007; 111: 769-809

23. Kanda Y, Kayama T, Okamoto S, et al. A post-marketing surveillance of $0.5 \%$ levofloxacin ophthalmic solution for external ocular infections. Rinsho Ganka 2008; 62 (13): 2007-17

Correspondence: Yoshiko Kanda, Safety Vigilance Group, Santen Pharmaceutical Co., Ltd., 3-9-19 Shimo-Shinjo, Osaka 533-8651, Japan. 